\title{
HIVIAIDS Interventions in Bangladesh: What Can Application of a Social Exclusion Framework Tell Us?
}

\author{
Nidhi Khosla \\ Department of Health, Behavior and Society, Johns Hopkins Bloomberg School of Public Health, 624 North Broadway, \\ Baltimore, MD 21205, USA
}

\begin{abstract}
Bangladesh has maintained a low HIV prevalence (of less than 1\%) despite multiple risk factors. However, recent serological surveillance data have reported very high levels of HIV infection among a subgroup of male injecting drug-users (IDUs). This suggests that an HIV/AIDS epidemic could be imminent in Bangladesh. Although biomedical and behavioural change projects are important, they do not address the root causes of observed risky behaviours among 'high-risk' groups. In Bangladesh, these groups include sex workers, IDUs, males who have sex with males, and the transgender population—hijra—who are all excluded groups. Using a social exclusion framework, this paper analyzed existing literature on HIV in Bangladesh to identify social, economic and legal forces that heighten the vulnerability of such excluded groups to HIV/AIDS. It found that poverty and bias against women are major exclusionary factors. The paper presents areas for research and for policy action so that the social exclusion of high-risk groups can be reduced, their rights protected, and an HIV epidemic averted.
\end{abstract}

Key words: Acquired immunodeficiency syndrome; Gender issues; HIV; Homosexuality; Needle-sharing; Sex behaviour; Social exclusion; Stigmatization; Bangladesh

\section{INTRODUCTION}

Recent work in the field of HIV and AIDS prevention and control in Bangladesh has highlighted the impending HIV epidemic in the country since the prevalence of HIV is rising among injecting drug-users (IDUs), with a grave risk of transmission to other groups in society (1). The vulnerabilities faced by IDUs, female sex workers (FSWs), and males who have sex with males (MSM) who are all high-risk groups have also been mentioned in the literature (2-4). While calls to increase awareness about HIV and AIDS and to increase the use of condoms and clean needles are important, these biomedical and behavioural interventions do not address the underlying root causes that lead to the observed behaviours among such high-risk groups. Poverty, stigma, lack of access to care, low educa-

Correspondence and reprint requests should be addressed to:

Ms Nidhi Khosla

Department of Health, Behavior and Society

Johns Hopkins Bloomberg School of Public Health

624 North Broadway

Baltimore, MD 21205

USA

Email: nkhosla@jhsph.edu

Fax: 1-410-502-4333 tion (3), gender inequality, and lack of a facilitative legal environment are various dimensions of exclusion of such high-risk groups that lead to risky sexual behaviours among them.

This paper employs a social exclusion framework to analyze the existing peer-reviewed and grey literature on HIV and AIDS in Bangladesh. It argues that the underlying exclusion of high-risk groups in Bangladesh must be addressed, if significant progress is to be attained in preventing an HIV epidemic in the country. The main contribution of the paper to the literature is the analysis of various forms of social exclusion faced by high-risk groups in Bangladesh and therein showing where policy actions can be targeted to address social exclusion and vulnerability to HIV and AIDS in Bangladesh.

The paper begins with a brief background on HIV statistics and government programmes in Bangladesh, followed by a description of the social exclusion framework. Following this, the various dimensions of exclusion in Bangladesh were analyzed with context to HIV infection. Next, the constraints and opportunities in tackling social exclusion in Bangladesh were examined. Finally, policy options for further research and tackling social exclusion in the context of HIV and AIDS in Bangladesh are presented. 


\section{HIVIAIDS IN BANGLADESH}

The first known case of HIV in Bangladesh was reported in 1986 (3). Soon after, the national HIV-prevention programmes were instituted. While over 450 HIV cases had been reported by 2003-2004, the actual number of people living with HIV and AIDS in Bangladesh may be around 7,500 (3). Bangladesh has remained a low-prevalence country, with an HIV prevalence of less than $1 \%$ in the general population, despite the presence of multiple risk factors (1). These risk factors include low level of knowledge on HIV and AIDS $(2,5)$, low use of condoms $(1,2,5,6)$, multiple sexual partners $(5,6)$, high incidence of sexually transmitted infections (STIs) $(2,5)$, poor blood safety $(5,7)$, risk of transmission from returned expatriates $(3,5,8)$, and the presence of HIV in neighbouring countries, such as India and Nepal $(2,3,5,8)$, with which Bangladesh shares not only cultural similarities but also a porous border. Recent data showed that the prevalence of HIV among IDUs has increased substantially which is alarming. In just 12 months (2005/2006), the prevalence of HIV among male IDUs increased from $4.9 \%$ to $7 \%$ in one city, and the prevalence in one neighbourhood in this city increased from $7.1 \%$ to $10.5 \%$ (1). This is just one of the indicators of the imminent danger of an HIV/AIDS epidemic to be faced by Bangladesh.

\section{GOVERNMENT RESPONSE TO ADDRESS HIV AND AIDS IN BANGLADESH}

In 1985, the Government of Bangladesh set up the National AIDS Committee (NAC) to provide policy direction and advice on all issues relating to HIV and AIDS, with representation from the highest political level, including the President of Bangladesh $(9,10)$. Although mainly a government body, the committee has representatives from non-governmental organizations (NGOs) and civil society. The committee developed the first National Strategic Plan (NSP) for the 1997-2002 period, endorsing the Universal Declaration of Human Rights as the basis for policy and action at all levels (10). Operationally, the coordinating body for HIV/AIDS programming in the country is the National AIDS/STD Programme (NASP) established under the Ministry of Health and Family Welfare $(9,10)$. This ministry acts as the Coordinating and Executive Body for STI/AIDS activities, and the Directorate General of Health Services is the implementing agency which acts through the NASP. The NASP mainly focuses on behaviour-change interventions for safer sexual practices and promotion of condoms (9).
The second National Strategic Plan for the 20042010 period was developed through a participatory process in May 2005. The strategic plan has identified five priority areas for HIV interventions in Bangladesh, which include support and services for priority groups, prevention of vulnerability to HIV, safe practices in the healthcare system, care and support services for people living with HIV/AIDS, and minimizing the impact of the HIV epidemic (10). Operational strategies have been identified in each of these areas, and a detailed three-year plan has been developed with assistance from the Joint United Nations Programme on HIV/AIDS (UNAIDS).

\section{SOCIAL EXCLUSION AND HIV}

In addition to the above-mentioned proximal behavioural risk factors, social exclusion of high-risk groups is a major problem in Bangladesh but is not always recognized as such. Social exclusion has been defined in various ways. The definitions put forth by Estivil (11) and Kabeer (12) are especially pertinent to this paper. Estivill has defined social exclusion as, "... an accumulation of confluent processes with successive ruptures arising from the heart of the economy, politics and society, which gradually distance and place persons, groups, communities and territories in a position of inferiority in relation to centers of power, resources and prevailing values" (11). This definition highlights that, first, social exclusion comprises dynamic processes (as opposed to social exclusion being a 'state') and is, therefore, by implication, actionable through directed policy interventions. Second, social exclusion has multiple dimensions, such as political, social and/or economic, and groups may be excluded along one or all of these dimensions. Estivill also asserts that there is a continuum that ranges from exclusion to inclusion, and groups or individuals may be relatively excluded or included along this continuum (11). Kabeer reflects upon social exclusion as "... the multiple and overlapping nature of the disadvantages experienced by certain groups and categories of the population" (12). These groups share a common social identity, such as religion/ ethnicity/caste or certain shared characteristics that are socially devalued. In the latter case, the individuals in these categories may not even know each other; female sex workers are an example of such a category.

In the field of HIV and AIDS prevention and care, the notion of 'stigma' is more readily understood than that of 'social exclusion'. Hence, it is important to distinguish between these terms before des- 
cribing social exclusion and HIV in Bangladesh. A recent study of attitudes of Thai nurses towards AIDS patients who have a history of illicit drug-use highlights the linkages between these terms (13). The authors say that social exclusion is "... something often characterized in terms of one group ensuring privilege over another through social processes that separate and distinguish between those groups that are fit to contribute and share community resources and those that are not. Conceived in these terms, stigma is the symbolic tagging of individuals or groups as sufficiently deviant from a social norm so as to legitimise their exclusion from community membership and social investment" (13). Social exclusion may not necessarily lead to stigma. As the section below elaborates, women in Bangladesh are socially excluded, although they do not suffer stigma while female sex workers in particular face both stigma and social exclusion.

\section{SOCIAL EXCLUSION AND HIV IN BANGLADESH}

The social exclusion faced by groups vulnerable to HIV infection in Bangladesh is of the second type outlined by Kabeer (12), i.e. discrimination faced by people sharing common behavioural or social characteristics. The socially-excluded people in Bangladesh in the context of HIV and AIDS are women, including sex workers, MSM, IDUs, hijra [The term is used in both singular and plural sense] people living with HIV/AIDS, and the very poor. These groups face multiple cultural/social, economic and legal discrimination, which is elaborated in detail in the following sections. Although women and the very poor may not face stigma per se, they are relatively socially devalued. Women in particular face exclusion from the formal economy, from access to healthcare, and from general participation in community life (14). This exclusion has inter-linkages with their heightened vulnerability to HIV and AIDS. In addition to the above groups, some agencies working on HIV prevention in Bangladesh also count migrant workers and transport-sector workers, such as truck-drivers, dock-workers, and rickshaw-pullers, as vulnerable to HIV infection (1). These latter groups may be socially excluded to various degrees in different social and economic settings.

\section{DIMENSIONS OF EXCLUSION IN BANGLADESH}

Social exclusion faced by high-risk groups is the result of overlapping disadvantages arising from the norms, values, and functioning of economic, social and legal institutions in Bangladesh. The institutional nature of discrimination is outlined below, followed by a discussion of how these overlap and reinforce the impact of each other.

\section{Economic institutions}

\section{Poverty}

In an environment of widespread poverty in Bangladesh, the poorest suffer the greatest exclusion. They have the least access to healthcare and health information, lesser means to protect themselves and have a lower health status compared to the rest of the population. Health programmes often do not reach the poorest. For instance, one study found that the richest male population group was twice as informed about HIV-prevention methods compared to the poorest (10). This is despite the fact that literature on HIV-prevention strategy designed for lower socioeconomic groups is available in Bangladesh. The information gap cited above may be partly explained by levels of higher education among the richer sections of the society or perhaps selective dissemination of information to the richer sections of the society. The latter is problematic as it reflects discrimination against the poor. Discrimination in the healthcare system has been self-reported by the poor as well, including disrespectful behaviour, poor quality of care, over-charging for services, and being wrongly charged for free services provided by the Government $(15,16)$. Poverty constrains access to prevention technologies, such as condomsordisposableneedles, forsafermedicalprocedures and blood transfusions $(7,10)$, except in a few areas, where the Government currently provides condoms and needles free of charge under the needle-exchange programme.

While institutional innovations such as microfinance have reduced poverty in Bangladesh, results of research have shown that the microfinance-lending institutions often miss the very or ultra-poor who do not satisfy the eligibility criteria for microcredit (17). As a result, these people miss many health benefits such as health education, which is associated with microcredit group membership (17).

Poverty is also an impetus for urban migration. Male out-migrants are typically young, often single, and with little education, which puts them at high risk of unsafe sexual practices such as unprotected sex with female sex workers or with other males (10). Recent studies assessing the risk-behaviours of married men working away from their families 
have found risky behaviour among both married women and men (8). After adjusting for sociodemographic variables, male migrants living away from their families within Bangladesh were 4.5 times (95\% confidence interval [CI] 2.8-7.1) more likely to have had extramarital sex than men who lived with their families (8). Male migrants living overseas were 6.2 times (95\% CI 3.8-10.2) more likely to have had extramarital sex than men who lived with their families (8). Among women, for those with husbands living away within Bangladesh, the odds of extramarital sex were 4.0 (95\% CI 2.0-7.9) and for those with husbands living overseas, the odds of extramarital sex were 3.6 (95\% CI 1.5-8.9) (8). The reference category was women living with their husbands.

\section{Social/cultural institutions}

\section{Bias against females}

In Bangladesh, social norms systematically accord a much lower status to females compared to males $(14,18)$. This discrimination has adverse implications for access of women to education, nutrition, health information, and services within and outside the household (14) and to demand safer sexual behaviour of their husbands. At the household level, the health of women is a lower priority than that of male household members, and healthcare for women is sought much less frequently than for men (15). These norms translate to exclusion of women from the healthcare system (15). Gender gaps in health information are reflected by indicators, such as knowledge of HIV-transmission routes among men being much higher than that among women (5), independent of economic stratum (10).

The case of anaemia in Bangladesh demonstrates how multiple disadvantages arising from economic and social (gender-based) exclusion overlap and contribute to the poor health of women and their vulnerability to HIV. Life-long inequity in nutrition and care makes females anaemic which, in turn, often necessitates blood transfusion after childbirth (14). Given the reluctance to invest in women's health, women often receive cheaper blood that has not been tested for HIV (15), thus putting them at risk for contracting HIV. Policy changes such as cost-recovery of healthcare services introduced with economic reforms in the last decade may create additional barriers to the health of women due to reluctance to pay for healthcare for women. Women also find it hard to negotiate the use of condoms or question sexual relations of their partner outside marriage, increasing their risk for STIs and HIV infection from their husbands (10). A study found that $0.8 \%$ of women attending basic healthcare clinics in Dhaka had active syphilis which is a risk factor for HIV (8).

Physical and sexual abuse from husbands is another risk factor for women. A recent study of over 3,000 married men currently living with their wives found that more than 1 in 3 married men had abused their wives physically or sexually in the past year (19). These men were more likely to report premarital or extramarital sex partners in the past year (adjusted odds ration $[\mathrm{AOR}]=1.80-3.45 ; 95 \%$ CI 1.20-8.23) and were more likely to report STI diagnosis or symptoms in the past year $(\mathrm{AOR}=1.68$ $2.52 ; 95 \%$ CI 1.24-3.73) compared to men who did not perpetrate violence (19). Further, men who inflicted physical violence and had contracted an STI were more likely (AOR=1.58; 95\% CI 0.93-2.70) not to disclose their condition to their wives compared to men not inflicting physical violence (19). This further constraints the ability of women to make informed choices and protect themselves from HIV infection.

The lower status of women also makes them vulnerable to being trafficked for sex work which is a potential risk for contracting HIV, in addition to other adverse health consequences (20). Little quantitative data exist on the number of women trafficked annually from Bangladesh; however, the estimated numbers are high. Trafficking for sex-work is again a reflection of social exclusion since it is facilitated by low levels of education and awareness among women; few marketable skills and, therefore, lower income-earning potential; and inadequate social protection mechanisms to avoid institutionalized violence such as sex-trafficking (21).

While some women are trafficked, others engage in sex work due to poverty. Estimates suggest that there are 100,000 female sex workers across Bangladesh (22). As elsewhere in Asia, sex work is stigmatized, and women find it impossible to return to mainstream society after working in this trade (23). The conditions in sex work in Bangladesh are extremely harsh. Both brothel and street-based sex workers earn low wages and face physical and verbal abuse and harassments from clients, brothelowners, police, and pimps $(22,23)$. Police often raid brothels under the pretext of searching for criminals and beat up sex workers, demand bribes, and otherwise harass workers and brothel-owners. Younger female sex workers are subjected to more violence than older workers, regardless of location (street or 
brothel). In 2002, 72\% of street-based sex workers aged less than 25 years and 34\% of street-based sex workers aged over 25 years were beaten or raped by police and hoodlums (22). Sex workers lack access to basic services, such as education, credit, sanitation, housing, and recreation. The consistent use of condoms is made difficult by the reluctance of clients to use condoms and fear of violence from clients. Carrying condoms also invites harassment from police (22). It is encouraging that several community-based groups of sex workers have been formed, in recent years, advocating for their basic rights as citizens of Bangladesh (22). This is likely to improve their well-being generally and also increase healthy behaviours, such as consistent and correct condom-use.

\section{Bias against other genders}

Persons who self-identify with a gender other than male or female are socially and economically marginalized in Bangladesh $(3,24)$. Traditionally, transgender population (hijra), despite suffering from a low social and economic status, played an important social role in providing entertainment at marriage and birth ceremonies (25). Modernization, however, has reduced their traditional earning opportunities. Given their low levels of education and skills, many now resort to high-risk sex work to survive. Hijra are threatened by local hoodlums and face verbal and physical abuse $(24,26)$. The harassment faced by hijra makes it difficult for them to carry and use condoms, and social discrimination makes it harder to reach this group with information on HIV prevention.

\section{Bias against males who have sex with males}

Male-to-male sexual behaviours in Bangladesh are not framed within Western concepts of homosexuality (3). Most males engaging in same-sex activity do not identify as homosexual or 'gay', nor do they belong to a homogenous community. Some adopt different sexual identities in different contexts, and many are married $(3,27,28)$. The reasons cited for male-to-male sexual practices in Bangladesh include sexual attraction to other males, preference for anal sex, inaccessibility of female sex partners, avoiding unwanted pregnancy, misconceptions about transmission of STIs and economic hardship (which makes inexpensive or free sex with males preferable to sex with female sex workers) (28).

MSM face social discrimination and legal persecution in Bangladesh, which compromises their physical, mental and sexual health. The stigma surround- ing homosexuality makes this a difficult-to-reach population subgroup (3). Islamic religious beliefs, hetero-normative pressures, and social norms demand that men be masculine and heterosexual. Deviations are unacceptable, and those who defy these norms face ridicule, physical and mental violence, and discrimination in educational, social and employment settings $(27,28)$. Homosexuality is a criminal offence which makes both MSM and health outreach staff who support them prone to frequent harassments from police and local hoodlums (27). The resulting environment of fear prevents vulnerable MSM from seeking information and services, such as treatment for STIs and counselling on adopting safer behaviours to reduce their risk of HIV infection (27). Cases of some MSM committing suicide due to discrimination have been reported (27). Double stigmatization occurs when MSM are diagnosed with HIV infection and have to cope with two ostracized identities.

\section{Stigma associated with injecting drug-use}

Injecting drug-use is considered a socially-deviant behaviour in Bangladesh. Stigma associated with injecting drug-use has a negative impact on the social acceptance of users and on job opportunities available to them, hindering their rehabilitation into the community $(29,30)$ and, thus, excluding them. It is possible that some revert back to druguse due to lack of acceptance into society. Further, facilities for detoxification for IDUs are inadequate, and this may be a reflection of the low priority that society places upon the welfare of this group. Government-run detoxification clinics in Bangladesh have a small capacity compared to the number of IDUs who want to quit and are reluctant to expand their services due to the high rates of relapse. These clinics advocate an abstinence-only approach that does not address the underlying factors that predispose people to drug-use. Private detoxification centres are prohibitively expensive for the poorer sections of the society (30).

\section{Stigma associated with HIV-positive status}

Widespread stigma and discrimination may act as a barrier to effective prevention since it deters people from seeking HIV-testing, disclosing their HIV-positive status (if known), seeking counselling, adopting safer sex practices, and seeking measures to prevent parent-to-child transmission (31). HIVpositive status attracts stigma in societies around the world (31), and Bangladesh is no different. In Bangladesh, HIV infection is associated with socially-deviant behaviours, such as sex outside marriage 
and drug-use (10). Lack of a cure or vaccine and insufficient awareness among the general population about transmission and prevention add to the fear associated with HIV and AIDS (32). Even persons with high knowledge on HIV and AIDS express stigma against HIV-positive persons. For instance, a study conducted in 1998 on knowledge and attitudes among staff of an international health research institution in Dhaka found that, while levels of awareness about modes of transmission and means of protection were satisfactory, attitudes towards HIV-infected people remained discriminatory (33). Forty percent of staff opposed the rights of an HIV-positive person to work (33).

\section{Legal institutions}

\section{Barriers against homosexual behaviour}

Exclusionary legal barriers with respect to HIV and AIDS in Bangladesh include Section 377 of the Penal Code that criminalizes homosexuality. This section states, "Whoever voluntarily has carnal intercourse against the order of nature with any man, woman or animal, shall be punished with imprisonment for life, or with imprisonment of either description for a term which may be extended to ten years, and shall also be liable to fine" (34). As a cognizable offence, police can arrest persons without a warrant based on information provided by a third party relating to the commission of such offences (35). Bail for this offence is at the discretion of the courts and can take up to two years to obtain. Since the definition of 'against the order of nature' is vague, cases are rarely booked under the Act. It contributes, however, to an environment in which some policemen are able to target MSM and outreach staff with blackmail, extortion, and abuse (27). This hinders MSM from accessing condoms, treatment for STIs, and counselling and testing services (27).

\section{Barriers against sex workers}

A second barrier to effective HIV prevention is the ambiguity in the legal status of brothels, which are neither legal nor illegal. 'Registered' brothels have been operating since the British regime $(22,23)$. Sex work in all other venues is illegal (3). This ambiguity makes harassment of sex workers easier and their access to healthcare services harder. It also prevents the creation of, and access to, workplace safety mechanisms for sex workers. In the absence of such structures, sex workers cannot negotiate safer work conditions and are subject to harassment from hoodlums, law-enforcing authorities, and brothel-owners alike. The outcome is poor physical and mental health and vulnerability to STIs and HIV. The insecurity created by the ambiguous illegal status of sex work was demonstrated by the increase in violence reported during 19982000, when large-scale moves were made to close brothels in Bangladesh (23). These moves and the resulting confusion reduced the perceived safety of the brothel-based industry. Some women started working on the streets, despite the increased risk of violence and reduced ability to use condoms outside brothels. During this time, the incidence of violence in brothels increased (23). While, in 1998, fewer than $1 \%$ of women reported forced sex by police; this figure went up to $6.8 \%$ in 2000 . Forced sex by mastans (local hoodlums) increased from $6.4 \%$ to $18.1 \%$ (23). Condom-use in brothels went down during this period, thus increasing the corresponding risk of STIs and HIV. While causality cannot be established here in strict epidemiological terms, less-frequent condom-use could be attributed to decreased confidence of workers given the significant insecurity caused by evictions and government dictates to close all brothels.

\section{Barriers against drug-users}

A third legal exclusionary barrier concerns IDUs. The Narcotics Control Act 1990 makes possession of tools used for taking drugs punishable with a minimum imprisonment for six months (30). Anecdotally, it is known that, in Bangladesh and in other countries, narcotics-control activities to reduce supply of illegal drugs more frequently target users rather than suppliers. This hinders the provision of counselling, detoxification, condoms, and clean needles to IDUs. Fortunately, some progress has been made in recent years by NGOs in advocating for a more supportive environment for outreach to IDUs. An amendment to the drug-use laws of Bangladesh, made in 2000, offered government support for NGOs which work with drug-users and detoxification and support for drug-users that seek to quit, under the existing health system (10). Needle-exchange programmes, such as those run by CARE Bangladesh, rely on strong advocacy with law-enforcement authorities (30).

\section{ROLE OF ACTORS IN MAINTAINING SOCIAL EXCLUSION}

The literature on social exclusion urges us to investigate the role of various actors at the local, national, regional and international levels that contribute directly or indirectly to maintaining exclusion (11). 
This can help identify areas and actors that can be targeted to reduce social exclusion.

At the international level, international development agencies have played a large role in development activities in Bangladesh since Independence in 1971. Since HIV/AIDS programmes began in 1986, these agencies have supported biomedical and behavioural interventions, such as promotion of condom and behaviour-change interventions, for high-risk groups (2). These activities are relatively more amenable to quantitative evaluation, such as project targets framed in terms of 'number of condoms distributed' or 'number of HIV information booklets produced and distributed'. From a reading of the grey and peer-reviewed literature, it appears that, in contrast, activities to counter stigma and discrimination experienced by high-risk populations are limited in scope and funding. It would appear then that, as a result of limited advocacy, the targeted high-risk groups would get labelled in the public mind as carriers of HIV infection and get further stigmatized. Thus, unintentionally, such internationally-funded programmes are creating further social exclusion. Such exclusion that is not deliberate has been termed 'passive exclusion' (11).

On the national level, while the NASP documents speak of reducing stigma, no special programmes appear to have been instituted to counter the social exclusion of high-risk groups. By omission, this may contribute to social exclusion of high-risk groups.

\section{OVERLAP AMONG DIFFERENT FORMS OF INSTITUTIONAL EXCLUSION}

While the different forms of institutional exclusion separately create vulnerability to HIV and AIDS, the overlap among these creates multiple and re-inforcing disadvantages for affected groups. The overlap between the multiple disadvantages faced by women in the 'general population' was illustrated earlier in the section on bias against females. Poverty is a feature common to all the socially-excluded groups vulnerable to HIV infection in Bangladesh. The overlap between exclusion of IDUs and economic exclusion is illustrated by the extremely high 7\% prevalence rate of HIV among IDUs in one location of the central city. Compared to IDUs from the rest of the city, these IDUs had lower socioeconomic status, were significantly less educated, and were more likely to be homeless (36). Their injecting behaviours were more risky than the average for that city, and they had a lower risk perception than their counterparts in other parts of the city.
Similarly, a study of female IDUs, some of whom were sex workers as well, showed that sex workers who also injected drugs faced more violence than female IDUs and were more likely to be incarcerated than female IDUs (4). Further, compared to male IDUs, there was greater overlap between the sex and drug-use networks for female IDUs, thus putting them at greater risk (4).

Similarly, MSM, hijra, and IDUs are at risk of HIV exposure due to the interactions between social, legal and economic exclusion and biomedical and behavioural risk factors of unsafe sexual and injecting practices. This exclusion creates legal barriers to providing necessary services, such as clean needles, condoms, and counselling; economic barriers in accessing facilities such as private drug-detoxification centres; and a social environment perpetuating fear, stigma, and ridicule.

\section{CONSTRAINTS AND OPPORTUNITIES IN TACKLING SOCIAL EXCLUSION}

The constraints to addressing social exclusion are entrenched in the nature of social biases both against groups, such as MSM, sex workers, and hijra, and against behaviours such as injecting drug-use. These biases have historical roots before the advent of AIDS. Legal constraints such as the Section 377 of the Penal Code which criminalizes homosexual behaviour are likewise difficult to remove. For instance, continuing initiatives in India by AIDS activists and human rights activists to remove the same Section 377 in the Indian Penal Code have been unsuccessful (37). However, change is possible. For instance, the Constitution of Bangladesh contains provisions for changing existing laws and policies if they are discriminatory or harmful. Advocacy efforts need to focus on such potentiallyhelpful provisions. Also in practice, there have been some positive advances, such as greater tolerance of law-enforcing authorities towards outreach activities held with IDUs (30). There needs to be greater dialogue among policy-makers and activists to create an enabling environment for eradicating these forms of social exclusion.

Policy documents on HIV and AIDS, produced by both Government, such as the Bangladesh Country Profile (2004) and by the National Strategic Plan for 2004-2010, and international development agencies make explicit mention of the need to address stigma, violation of rights, and to create an enabling environment for HIV prevention in Bangladesh. However, there has not been a concomitant 
increase in funding for such activities, which would have demonstrated a real commitment to these issues. A budget analysis exercise can help reveal the percentage and amount of funds that are being used for addressing violations of human rights and stigma against vulnerable groups. This will help agencies see for themselves how their money is being spent and where it may be better used.

Outside the government sector, the sector comprising NGOs, civil society, the community, and development organizations has supported and is continuing to support a large number of HIV-prevention programmes. There is diversity in the type of NGOs that have been working in HIV prevention in Bangladesh, and their numbers are not constant due to changes in funding, among other reasons (2). Some developed organically within existing NGOs or in organizations established specifically to respond to stigma, discrimination, denial and lack of services. Others were donor-initiated and funded projects, prioritized according to development or aid strategies that the agencies had formulated for Bangladesh. Some are implemented (through partner NGOs) by international agencies, such as Family Health International and CARE, scaled up based on international programmes. Most of these NGOs focus on traditional biomedical and behavioural interventions while others focus on mitigating the impact of social exclusion on vulnerable groups and, in some cases, attempt to address the root causes of exclusion itself. A coalition network comprising about 135 of these NGOs has also provided coordination support to supplement activities of the Government (10), thus demonstrating inter-sectoral collaboration. The budgetary outlay of these various NGO programmes is not known, and there is little publicly-available documentation of the process and impact evaluation (findings often being for internal use only). Only some of these programmes are informed by formal quantitative and qualitative research while others are driven perhaps by an observation of social trends and lived experiences of those having social discrimination. Some NGOs have sought to adapt best practices from elsewhere to the local context. NGO programmes have included outreach services to sex workers; services for IDUs, such as management of abscess, creating awareness about safer practices, provision of clean needles, counselling, and drop-in centres (30,38); services for MSM, such as counselling, provision of condoms, creating awareness about safer practices, creating networks of MSM, dropin centres, health clinics, and social activities (26); and networks for positive people to foster mutual support and share information and services for the hijra, such as skill-building, confidence-building, and counselling (26). This list is illustrative of the examples of work currently ongoing in Bangladesh and is not meant to be exhaustive.

There are minimal corporate-sector efforts to curb HIV and AIDS in Bangladesh, although a very recent public-private partnership has emerged between the UNAIDS and a large telecommunications provider. Individual donations to care programmes for HIV-positive people have also been reported anecdotally.

Policies and responses to address social exclusion should focus both on addressing the root causes of exclusion of these populations and address the impact of this exclusion, such as unemployment or inability to negotiate condom-use. An eight-point agendum is presented below.

- First, poverty must be addressed. Tackling poverty is frequently missing in HIV programmes and must be specifically addressed at the planning stage of a programme and be continually monitored.

- Second, the Government should play a more facilitative role in developing the capabilities of NGOs since they have been found to be more effective in service-delivery in Bangladesh.

- Third, NGOs should be encouraged to use a social exclusion and human rights framework to guide their programmes and devise measurable indicators so that progress against goals can be assessed. Advocacy efforts for the rights of excluded groups must systematically document human rights abuses and disabling laws and policies so that information can be synthesized and presented to policy-makers as evidence of social exclusion. Existing knowledge in Bangladesh, such as the mapping exercise completed by the Institute of Law, Ethics in Medicine (National Law School, Bangalore) and the Institutional Development of Human Rights in Bangladesh (Ministry of Law, Justice and Parliamentary Affairs), reviewing discrimination in existing laws, codes, regulations, judicial decisions, and notifications, needs to be acted upon (10).

- Fourth, advocacy efforts to address legal barriers against sex work, MSM, and IDUs must 
continue. The experience of Bangladesh with the National Syringe Exchange Programme (NSEP) has shown that, with advocacy, working compromises between the law and what is required for public health, can be arrived at.

- Fifth, research should focus on understanding the constructions of socially-devalued identities and categories, motivations for high-risk behaviour, influences on access to healthcare, social stresses, and how emerging crises such as HIV worsen social exclusion for already-vulnerable groups. Unless special effort is made to understand these identities and behaviours, interventions may work adversely to increase the isolation of excluded groups. Such research should be community-based and effect positive changes in their situation. Research being conducted by ICDDR,B with hijra and with MSM are examples of ethically-grounded work that seeks to identify barriers to safe sex in social, cultural, economical, religious, political and structural contexts.

- Sixth, community-based organizations need to be strengthened to articulate their own agenda based on experienced needs, instead of passively accepting recommendations of donors. This requires commitment from research institutions and NGOs to knowledge transfer and capacity-building of community-based organizations (CBOs). Service-delivery for excluded groups should consider factors, such as traveltime, ease of contact, and cost, in scheduling when and where services are available. These may differ for groups, such as sex workers or MSM, who may only be able to access these during certain hours.

- Seventh, interventions to reduce social exclusion may also be planned in a serial manner. Once some success has been achieved in reducing exclusion for a stigmatized group, there should be attempts to provide services through common delivery-points so that inclusion can be fostered. Eventually, a mix of targeted and common interventions will be required to reduce social exclusion from healthcare. For instance, this author has experience of working under the aegis of ActionAid India on a project with the Musahar community-a very poor group that is socially excluded within the dalit community. [Dalit is a term of assertion used by communities that were considered untouchables under the Hindu caste system in India. Despite official abolishment of this practice and various development programmes for them, their exclusion continues]. Initial efforts focused on mobilizing the community and providing leadership training after which ActionAid started providing services such as healthcare camps that were open to all members of the village but were held in the Musahar hamlets. These camps, thus, prioritized the excluded groups but also provided a social space to enable interaction, acceptance, and cooperation among the mainstream and excluded groups.

- Eighth, linkages among activists and groups, such as Parliamentarians for Global Action and Bangladesh Parliament Members Support Social Group on Prevention of HIV/AIDS and Human Trafficking, should be strengthened. Stakeholders, such as the Department of Narcotics, Ministry of Education, Ministry of Transport, Ministry of Religious Affairs, and community leaders and opinion makers, have an important role to play in HIV prevention. Business and private-sector involvement in the AIDS epidemic needs to be explored and encouraged, especially given the rapid urbanization giving rise to new industries, such as ready-made garments where over one million young women work.

\section{Limitations}

This paper is based on an analysis of existing data and does not present fresh statistical data. Statistical data cited here support that high-risk groups are excluded but cannot 'prove' it, and further documentation is recommended. Second, there are limitations to the existing data since changes in procedures mean that the national surveillance data are not always comparable. However, the thrust of the paper is not statistical, and hence, these limitations should not prove to be major.

\section{CONCLUSIONS}

The dangers posed by the spread of the AIDS pandemic merit application of approaches from various disciplines to develop a more comprehensive understanding of the causal mechanisms of the spread of the epidemic and to frame effective prevention measures. The vulnerability of high-risk groups has already been noted in the literature. A social exclusion framework deepens this understanding beyond the current level to investigate the social, cultural and legal disadvantages that 
predispose high-risk groups to HIV/AIDS. The utility of applying a social exclusion approach to HIV/ AIDS in Bangladesh lies in its ability to identify the underlying exclusionary forces in social, economic and legal institutions, which create the social, economic and emotional conditions that produce and reinforce the risk of HIV infection.

The use of a social exclusion lens on existing information generates important knowledge and policy implications regarding targeted prevention efforts. For instance, we learn about the different dimensions of exclusion faced by women and the very poor, two 'populations' that often do not find as much mention in the HIV literature as the highrisk groups. Increasing the availability of condoms or imprisoning IDUs is unlikely to further HIV prevention if concomitantly the factors that predispose people to HIV risk are not addressed. Policy development to safeguard human rights in Bangladesh should be informed by what violations are happening, in which institutions and through which actors, thereby making the issues of stigma and discrimination more specific and actionable. On the part of researchers and academics, a strengthening of frameworks to guide the investigation of social factors such as exclusion and to produce more appropriateresearch is needed. Acomprehensiveyet adaptable model of social exclusion and health should clarify the mechanisms by which social exclusion generates adverse health outcomes and how these adverse outcomes may exclude people and generate health inequities. The theory or model must offer specific recommendations for entry-points for intervention and policy action on social exclusion.

It is imperative now to use the opportunities provided by the current low prevalence of HIV in Bangladesh and the existing prevention programmes. Unless serious measures are undertaken to address the risk faced by socially-excluded groups, the infection is likely to spiral. A social exclusion analysis can give a new impetus to prevention efforts by highlighting the multiple disadvantages faced by high-risk groups and to enable socially-just health programmes.

\section{ACKNOWLEDGEMENTS}

The author thanks the reviewers and Jonathan B Kotch, Heidi Bart Johnston, Sharful Islam Khan, and Jo Grzelinska for their comments on this analysis. This work was made possible through funding provided by the World Health Organization (WHO) and undertaken as work for the Social Exclusion Knowledge Network established as part of the WHO's Commission on the Social Determinants of Health. The views presented in this work are those of the author and do not necessarily represent the decisions, policy, or views of WHO or Commissioners or other sponsors. Other sponsors for this work include (a) Rotary Foundation under the Rotary World Peace Fellowship, (b) Center for Global Initiatives at the University of North Carolina at Chapel Hill through the International Internship Award, and (c) Sommers Scholar Program of the Johns Hopkins Bloomberg School of Public Health, Baltimore, Maryland, USA.

\section{REFERENCES}

1. Azim T, Rahman M, Alam MS, Chowdhury IA, Khan $\mathrm{R}$, Reza $\mathrm{M}$ et al. Bangladesh moves from being a lowprevalence nation for HIV to one with a concentrated epidemic in injecting drug users. Int J STD AIDS 2008;19:327-31.

2. Islam MM, Conigrave KM. HIV and sexual risk behaviors among recognized high-risk groups in Bangladesh: need for a comprehensive prevention program. Int J Infect Dis 2008;12:363-70.

3. Chan PA, Khan OA. Risk factors for HIV infection in males who have sex with males (MSM) in Bangladesh. BMC Public Health 2007;7:153.

4. Azim T, Chowdhury EI, Reza M, Ahmed M, Uddin MT, Khan R et al. Vulnerability to HIV infection among sex worker and non-sex worker female injecting drug users in Dhaka, Bangladesh: evidence from the baseline survey of a cohort study. Harm Reduct J 2006;3:33.

5. Rahman MS, Rahman ML. Media and education play a tremendous role in mounting AIDS awareness among married couples in Bangladesh. AIDS Res Ther 2007;4:10.

6. Gibney L, Choudhury P, Khawaja Z, Sarker M, Vermund SH. Behavioural risk factors for HIV/AIDS in a low-HIV prevalence Muslim nation: Bangladesh. Int J STD AIDS 1999;10(3):186-94.

7. Gibney L, Choudhury P, Khawaja Z, Sarker M, Islam $\mathrm{N}$, Vermund SH. HIV/AIDS in Bangladesh: an assessment of biomedical risk factors for transmission. Int J STD AIDS 1999;10:338-46.

8. Mercer A, Khanam R, Gurley E, Azim T. Sexual risk behavior of married men and women in Bangladesh associated with husbands' work migration and living apart. Sex Transm Dis 2007;34:265-73.

9. Mamtaz A. HIV/AIDS: response to the pandemic in Bangladesh. J Prev Soc Med 1999;18:74-83.

10. Bangladesh. Ministry of Health and Family Welfare. Directorate General of Health Services. National AIDS/STD Programme. Bangladesh country profile on HIV and AIDS 2004. Dhaka: National AIDS/STD 
Programme, Directorate General of Health Services, Ministry of Health and Family Welfare, Government of Bangladesh, 2004. 64 p.

11. Estivill J. Concepts and strategies for combating social exclusion: an overview. Geneva: International Labour Organization, 2003. 137 p.

12. Kabeer N. Social exclusion and the MDGs: the challenge of 'durable inequalities' in the Asian context. In: Asia 2015 Conference: Promoting Growth, Ending Poverty, March 2006. London: Institute of Development Studies, 2006. 30 p.

13. Chan KY, Stoové MA, Reidpath DD. Stigma, social reciprocity and exclusion of HIV/AIDS patients with illicit drug histories: a study of Thai nurses' attitudes. Harm Reduct J 2008;5:28.

14. Kibria N. Culture, social class, and income control in the lives of women garment workers in Bangladesh. Gender Soc 1995;9:289-309.

15. Schuler SR, Bates LM, Islam MK. Paying for reproductive health services in Bangladesh: intersections between cost, quality and culture. Health Policy Plan 2002;17:273-80.

16. Bates LM, Islam MK, Al-Kabir A, Schuler SR. From home to clinic and family planning to family health: client and community responses to health sector reforms in Bangladesh. Int Fam Plan Perspect 2003;29: 88-94.

17. Rahman A, Razzaque A. On reaching the hardcore poor: some evidence on social exclusion in NGO programmes. Bangladesh Dev Stud 2000;26:1-35.

18. Amin S, Diamond I, Naved RT, Newby M. Transition to adulthood of female garment-factory workers in Bangladesh. Stud Fam Plann 1998;29:185-200.

19. Silverman JG, Decker MR, Kapur NA, Gupta J, Raj A. Violence against wives, sexual risk and sexually transmitted infection among Bangladeshi men. Sex Transm Infect 2007;83:211-5.

20. Sarkar K, Bal B, Mukherjee R, Chakraborty S, Saha S, Ghosh A et al. Sex-trafficking, violence, negotiating skill, and HIV infection in brothel-based sex workers of eastern India, adjoining Nepal, Bhutan, and Bangladesh. J Health Popul Nutr 2008;26:223-31.

21. Dasgupta A. Bangladesh: the blindfolded journey to ruins. (http://www.youandaids.org/Features/Blindfolded JourneytoRuins.asp, accessed on 1 December 2008).

22. Hosain GM, Chatterjee N. Beliefs, sexual behaviours and preventive practices with respect to HIV/AIDS among commercial sex workers in Daulatdia, Bangladesh. Public Health 2005;119:371-81.

23. Jenkins C, Rahman H. Rapidly changing conditions in the brothels of Bangladesh: impact on HIV/STD. AIDS Educ Prev 2002;14(3 Suppl A):97-106.
24. Bandhu Social Welfare Society. Final technical report. Third Consultation Meeting on MSM sexual health and capacity building. Dhaka: Bandhu Social Welfare Society, 2006. 34 p.

25. Bangladesh. Ministry of Health and Family Welfare, Directorate General of Health Services, National AIDS/STD Programme. Report on the Second National Expanded HIV Surveillance, 1999-2000, Bangladesh. Dhaka: National AIDS and STD Programme, Ministry of Health and Family Welfare, Government of Bangladesh, 2000. 86 p.

26. Bandhu Social Welfare Society. Let's join hands against AIDS: annual report January-December 2004. Dhaka: Bandhu Social Welfare Society, 2005. 28 p.

27. Ahmed S. Social justice and the human rights of MSM in Bangladesh. In: Siddiqi DM, editor. Human rights in Bangladesh. Dhaka: Ain o Salish Kendra, 2003:235-45.

28. Khan SI, Hudson-Rodd N, Saggers S, Bhuiya A. Men who have sex with men's sexual relations with women in Bangladesh. Cult Health Sex 2005;7:159-69.

29. Aziz A. Waking up to reality: cover story. Star Weekend Magazine (Dhaka) 2005;4(72). (http://www.thedailystar.net/magazine/2005/11/03/cover.htm, accessed 1 December 2008).

30. Knight VC, editor. Drug users at risk to HIV. Documenting our experience 2000-2005: report. Dhaka: CARE, Bangladesh, 2006. 31 p.

31. Cáceres CF, Aggleton P, Galea JT. Sexual diversity, social inclusion and HIV/AIDS. AIDS 2008;22(Suppl 2):S45-55.

32. Joint United Nations Programme on HIV/AIDS. At risk and neglected: four key populations. In: Report on the global AIDS epidemic. Geneva: Joint United Nations Programme on HIV/AIDS, 2006:103-22.

33. Islam MT, Mostafa G, Bhuiya AU, Hawkes S, de Francisco A. Knowledge on, and attitude toward, HIV/ AIDS among staff of an international organization in Bangladesh. J Health Popul Nutr 2002;20:271-8.

34. Bangladesh sodomy laws. (http://www.glapn.org/ sodomylaws/world/bangladesh/ bangladesh.htm, accessed on 1 December 2008).

35. Amin A. Criminal responsibility for torture under Bangladesh law. (http://www.thedailystar.net/ law/2004/06/04/opinion.htm, accessed 1 December 2008).

36. Azim T, Hussein N, Kelly R. Effectiveness of harm reduction programmes for injecting drug users in Dhaka city. Harm Reduct J 2005;2:22.

37. Steinbrook R. HIV in India-a complex epidemic. $N$ Engl J Med 2007;356:1089-93.

38. Foss AM, Watts CH, Vickerman P, Azim T, Guinness $\mathrm{L}$, Ahmed $\mathrm{M}$ et al. Could the CARE-SHAKTI intervention for injecting drug users be maintaining the low HIV prevalence in Dhaka, Bangladesh? Addiction 2007;102:114-25. 